\title{
Orientation of Microvascular Blood Flow in Pancreatic Islet Isografts
}

\author{
Michael D. Menger, Peter Vajkoczy, Carmela Beger, and Konrad Messmer \\ Institute for Surgical Research, University of Munich, 8000 Munich 70, Federal Republic of Germany
}

\begin{abstract}
There is evidence that intraislet cellular communication and hormone delivery within the islets of Langerhans is controlled via capillary perfusion directed from the $B$ cell core to the $A / D$ cell mantle (intraislet portal system). To determine whether vascularization of freely transplanted islets repeats this "coreto-mantle" capillary perfusion, hamster islets were isolated by collagenase digestion and transplanted into a skinfold chamber of syngeneic animals $(n=12) .14 \mathrm{~d}$ after transplantation, the microvasculature of the islet grafts was analyzed by in vivo fluorescence microscopy. The capillary glomerulum-like network of the islet grafts $(n=109)$ was found supplied by individual arterioles, which regularly pierced the islet and broke into capillaries within the graft $(96 / 109[88.1 \%])$, resulting in capillary flow directed from the core to the islet's periphery. Only in 13 of 109 islets (11.9\%) arterioles broke into capillaries at the outside margin of the islet and capillary flow was directed simultaneously to vessels located within the core, as well as the periphery of the graft. The islet's capillary network was drained by individual venules and intercapillary anastomoses between the newly formed islet capillaries and the preexisting capillaries of the host muscle tissue. Immunohistochemical staining revealed $B$ cells located within the core, and $A$ and $D$ cells scattered in the periphery of the islets, indicating reestablishment of sequential $B \rightarrow A / D$ cellular perfusion of the grafts. Thus, freely transplanted islets develop an intra-islet portal system, similarly to that of pancreatic islets in situ. (J. Clin. Invest. 1994. 93:2280-2285) Key words: microcirculation • islets • transplantation • in vivo microscopy • hamster
\end{abstract}

\section{Introduction}

Hormone delivery within islets of Langerhans is controlled via the direction of islet cellular perfusion rather than paracrine interactions in the interstitial space (1). The intraislet portal system, which determines the order of microvascular perfusion, has been proposed to play the pivotal role in intraislet cellular communication, in particular according to the regulation of islet hormone secretion (2).

Bonner-Weir and Orci (3) have been first to demonstrate that the islet's afferent arterioles do not break into capillaries at

Address correspondence to Prof. Dr. Michael D. Menger, Institut für Chirurgische Forschung, Universität des Saarlandes, D-66421 Homburg/Saar, Federal Republic of Germany.

Received for publication 12 April 1993 and in revised form 27 December 1993.

J. Clin. Invest.

(c) The American Society for Clinical Investigation, Inc.

$0021-9738 / 94 / 05 / 2280 / 06 \$ 2.00$

Volume 93, May 1994, 2280-2285 the level of non-B (glucagon, somatostatin, and pancreatic polypeptide) cells, but enter the islets at discontinuities of the mantle of non-B cells, and form capillaries within the B cell mass, which then traverse the B cell core, before passing through the opposite non-B cell mantle. This intraislet portal system, characterized by (uni)directional "core-to-mantle" islet capillary perfusion, results in a sequential $B \rightarrow A \rightarrow D$ islet cellular perfusion $(1,2)$, which allows for the regulation of the net secretion of insular hormones, thereby maintaining systemic glucose homeostasis.

Transplantation of pancreatic islets represents an attractive approach for curative treatment of insulin-dependent diabetes mellitus. In rodents, a remarkable number of experimental studies have demonstrated reversal of diabetes and restoration of glucose metabolism (4); however, studies in larger animals and clinical attempts have been less successful $(5,6)$. Beside isolation of a sufficient mass of islets ( $B$ cells) and prevention of graft rejection, adequate microvascularization of the grafts has been suggested to be a major obstacle in achieving successful islet transplants (7-9). In contrast to heart, liver, kidney, or whole pancreas organ grafts, which are revascularized immediately upon reperfusion after the transplantation procedure, freely grafted islets require the process of angiogenesis and revascularization to establish adequate microvascular blood supply (10). Samols and co-workers (9) have proposed that the adequate blood supply to the islet transplant represents a "sine qua non" for graft function and survival, and may determine the quality of regulatory control of islet hormone secretion.

Previous studies have demonstrated that freely grafted islets are revascularized within a time period of 10-14 d (11); however, there is no information about whether the "core-to-mantle" microvascular perfusion ( $\rightarrow A \rightarrow D$ islet cellular perfusion) is reestablished in grafted islets according to the perfusion characteristics of pancreatic islets in situ. Herein, we present first evidence that in freely transplanted hamster islet isografts, $(a)$ intraislet cellular composition, (b) micro-angio-architecture, and $(c)$ direction of capillary blood perfusion are similar as known for pancreatic islets in situ. Using immunohistochemical techniques, we demonstrate that within the transplanted islets B cells are localized in the core of the graft, while A and D cells are scattered throughout its periphery (mantle of the islet). Furthermore, we demonstrate by in vivo fluorescence microscopy that the micro-angio-architecture of these grafts is characterized by a glomerulum-like network of capillaries presenting microvascular flow preferentially directed from the B cell core to the A/D cell mantle of the islets.

\section{Methods}

Pancreatic islets were isolated from Syrian golden hamsters (60-80 g body $w t$ ) using a modified collagenase digestion technique (11). The 
animals were anesthetized with $50 \mathrm{mg} / \mathrm{kg}$ sodium pentobarbital ( Nembutal; Abbott Laboratories, North Chicago, IL) intraperitoneally, and the pancreas was removed after perfusion with $3 \mathrm{mg}$ of neutral red (Sigma Chemical Co., St. Louis, MO) dissolved in $20 \mathrm{ml}$ of Hanks' solution (H6136; Sigma Chemical Co.) via the abdominal aorta. The excised gland was cut into $\sim 30-40$ pieces, and the tissue was desintegrated by $20 \mathrm{mg}$ of collagenase from Clostridium histolyticum (Serva Feinbiochemica GmbH \& Co., Heidelberg, FRG) dissolved in $5 \mathrm{ml}$ of Hanks' solution $\left(37^{\circ} \mathrm{C}, 10-15 \mathrm{~min}\right)$. The digest was then sedimented three times in ice-cold Hanks' solution. Handpicking of the isolated islets guaranteed single exocrine-free grafts for transplantation (11).

8-10 isolated islets, evenly distributed in size $(150-200 \mu \mathrm{m})$, were transplanted into the dorsal skinfold chamber of syngeneic animals ( $n$ $=12$ ). The chamber and its implantation procedure have been described by Endrich et al. (12) in detail. Briefly, under pentobarbital anesthesia $(50 \mathrm{mg} / \mathrm{kg}$ body wt i.p.; Abbott Laboratories), the animals are fitted with two symmetrical titanium frames, positioned on the dorsal skinfold, sandwiching the extended double layer of skin. One layer of skin and the retractor muscle are completely removed in a circular area of $\sim 15 \mathrm{~mm}$ in diameter, and the remaining tissue (consisting of skin muscle and subcutaneous tissue) are covered with a removable coverslip, which is incorporated into one of the titanium frames. As demonstrated in previous studies $(11,13,14)$, the skinfold preparation is a valid model for the intravital microscopic study of the microvasculature of free pancreatic islet grafts, in which the skin muscle serves as bed for the transplants. The technique allows for quantitative analysis of all microvascular segments of individual islet grafts, including supplying arterioles, nutritive capillaries, and postcapillary venules (15).

For intravital fluorescence microscopy, while awake, the animals were immobilized in a plexi-glass tube, and the skinfold preparation, containing the islet grafts, was attached to the microscope stage. After contrast enhancement by means of FITC-labeled dextran $(0.2 \mathrm{ml} 5 \%$ solution, intravenous injection (jugular vein), $M_{\mathrm{r}}$ 150,000; Sigma Chemical Co., St. Louis, MO) in vivo microscopy was performed using a modified Leitz Orthoplan microscope with a $100-\mathrm{W}$ mercury lamp attached to a Ploemo-Pak illuminator with an $\mathrm{I}_{2}$ blue filter block (Leitz, Wetzlar, FRG) for epiillumination. The observations were recorded by means of a low light level, $1 / 2$-inch format charge-coupled device camera (FK 6990; Prospective Measurements, San Diego, CA) and transfered to a video system for off-line evaluation. Analysis of the islet's microvascular blood perfusion was performed after the process of revascularization was completed on day 14 after transplantation. Analyses included determination of $(a)$ number and diameter of arteriolar blood vessels; $(b)$ angio-architecture of capillary network; $(c)$ direction of capillary perfusion and capillary transit time; and $(d)$ number and morphology of the islet's draining blood vessels.

The diameter of microvessels was measured by a computer-assisted image analysis system (CAMAS; Zeintl, Neckargmünd, FRG). The angio-architecture of the capillary network was classified in three categories. Category 1 includes islets presenting with arterioles, which break into capillaries at the outer margin of the islet's glomerulum-like microvasculature (Fig. $1 \mathrm{~A}$ ). Category 2 includes islets with the arterioles penetrating the islet's peripheral vasculature (mantle) and breaking into capillaries within the graft (at the core/mantle interface or within the core of the islet), which then traverse the core before perfusing the islet's periphery (Fig. $1 B$ ). Category 3 includes islets presenting with arterioles, which pierce into the center of the islet and break into capillaries, which then radially traverse the islet core to its periphery (Fig. $1 C$ ). Within all islets investigated, direction of capillary blood flow was determined by "slow motion" analysis; capillary transit time was measured in one of the islets of each animal $(n=12)$ by "frame-toframe" analysis at the first pass of the fluorescent compound (FITCdextran 150,000).

After in vivo microscopy, the tissue containing the islet grafts was excised and fixed in $10 \%$ formaldehyde for light microscopy and immunohistochemical staining. After $24 \mathrm{~h}$, the preparations were dehydrated through a graded series of alcohol, embedded in paraffin, and sectioned

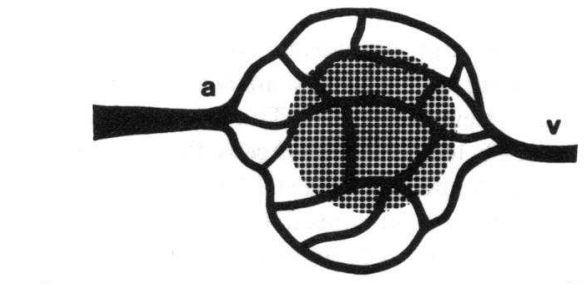

A

category 1

B

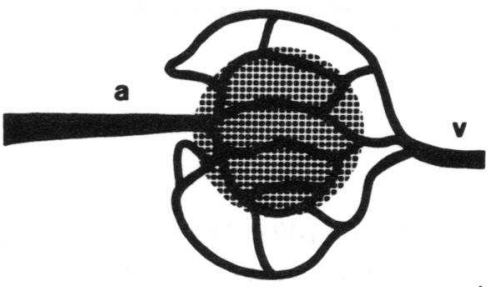

category 2

C

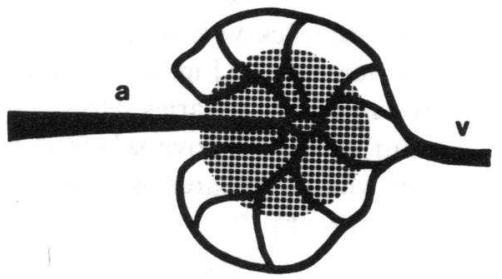

category 3

Figure 1. Classification of capillary angio-architecture of syngeneic islet grafts (gray areas denote the B cell core). $(A)$ Category 1: the supplying arteriole $(a)$ breaks into capillaries at the outer margin of the islet, and capillary perfusion is directed simultaneously to vessels located within the core and the periphery of the graft. Blood flow is collected by postcapillary venule $(v)$. $(B)$ Category 2 : the supplying arteriole penetrates the islet's periphery (mantle) and breaks into capillaries within the islet (at the core/mantle interface or within the core of the islet). Capillaries traverse the core of the islet before passing through the non-B cell mantle, and are drained by postcapillary venule. $(C)$ Category 3: the supplying arteriole pierces into the center of the islet and breaks into capillaries, which then radially traverse the islet core towards the islet's periphery. Blood flow is collected by postcapillary venule.

at $3 \mu \mathrm{m}$ thickness. Intracellular content of insular hormones was demonstrated immunohistochemically (peroxidase-technique) $(13,16)$ by means of polyclonal anti-insulin, anti-glucagon, and anti-somatostatin antibodies, which have been shown to selectively detect the individual insular hormones of hamster islets (17). For the detection of intracellular insulin, the dewaxed sections were incubated with a polyclonal guinea pig anti-porcine insulin antibody (1:200; Dako Corporation, Hamburg, F.R.G.). Cross reactivity of the anti-porcine insulin antibody with hamster and antigen specifity to insulin was confirmed by Western blotting. A peroxidase-conjugated rabbit anti-guinea pig IgG (1:50; Dako Corporation) was used as secondary antibody. Intracellular glucagon and somatostatin were detected by a polyclonal rabbit anti-porcine glucagon ( 1:50; Milab, Malmö, Sweden) and a polyclonal rabbit anti-human somatostatin (1:400; Dako Corporation ) antibody, respectively. Specimens were then reacted serially with a biotinylated secondary mouse anti-rabbit IgG and an avidin-biotin-horseradish peroxidase complex (both diluted according to the manufacturer's instructions; Vector Laboratories Inc., Burlingame, CA ). Finally, all specimens were stained with 3-amino-9-ethylcarbazole (Sigma Chemical Co.), DMSO, $\mathrm{H}_{2} \mathrm{O}_{2}$ (Merck, Darmstadt, F.R.G.), and were counterstained with hemalaun (Merck). Controls were performed without pri- 
mary and secondary antibodies to exclude nonspecific staining. The spatial arrangement of glucagon- and somatostatin-positive cells and cell clusters within 42 islets were quantitatively analyzed by a computer-assisted image analysis system (CAMAS). To evaluate the ratio of peripherally vs nonperipherally located A and D cells, the area representing the rim of the islets was defined by the distal $10 \%$ of the diameter of the graft (one to two cell layers), and positively stained cells and cell clusters were classified according to peripheral or nonperipheral location.

Data are given as mean \pm SD. Comparisons were performed using Mann-Whitney $U$ test; differences were considered significant at a $P$ $<0.05$ level.

\section{Results}

$14 \mathrm{~d}$ after transplantation $94 \%(109 / 116)$ of the islet grafts revealed complete vascularization (Figs. $2 C$ and $3 C$ ). The glomerulum-like network of capillaries was supplied by one or two individual arterioles, the diameters ranging between 9 and $30 \mu \mathrm{m}$ ( Table I). The feeding arterioles were arranged in parallel with the capillaries of the host tissue (Fig. $3 \mathrm{C}$ ), indicating their origin from the striated muscle capillaries. However, the mean diameter $(16.8 \pm 3.0 \mu \mathrm{m})$ of the microvessels feeding the islets was significantly larger when compared with those supplying the muscle tissue $(5.3 \pm 0.8 \mu \mathrm{m}, P<0.01)$.

Analysis of capillary angio-architecture and direction of capillary blood flow revealed that islets of category $2(68 / 109$ [62.4\%]) and $3(28 / 109[25.7 \%])$, but not category $1(13 / 109$ [11.9\%]), presented with unidirectional "core-to-mantle" perfusion. Arterioles of islets classified category 2 broke into capillaries within the islet, and capillaries traversed the core of these islets before passing through the non-B cell mantle (Fig. 2). Arterioles of islets classified category 3 broke into capillaries at the center of the islet, and capillaries traversed the islet radially from the core to its periphery (Fig. 4). Only 13 of the total of 109 islets were classified category 1 , in which the arterioles broke into capillaries at the outer margin of the microvascular network, and capillary perfusion was directed simultaneously to vessels located within the core and the periphery of the graft (Fig. 3). 60\% (65/109) of the islets presented with an efferent microvessel of capillary structure, running along the periphery of the graft's microvasculature (Fig. $2 C$ ). The mean capillary transit time was $1.57 \pm 1.28 \mathrm{~s}$ with a range from 0.54 (category-3 islet) to $5.16 \mathrm{~s}$ (category-1 islet). Capillary transit time was found lowest in islets classified category $3(0.82 \pm 0.40 \mathrm{~s} ; n=4)$ when compared to islets of category $2(1.55 \pm 0.43 \mathrm{~s} ; n=6)$ and category $1(3.13 \pm 2.87 \mathrm{~s} ; n=2)$.

The islet's capillary network was drained by individual venules, and, in analogy to the insulo-acinar portal system, by intercapillary anastomoses between the newly formed islet capillaries and the autochthonous muscle capillaries (Fig. 2). Quantitative analysis revealed that all islets were drained by one to six individual venules with diameters ranging between 11 and $48 \mu \mathrm{m}$ (Table I). Concomitantly, 85\% (93/109) of the grafts showed anastomoses between islet and muscle capillaries.

Immunohistochemical staining confirmed that B, A, and D cells are not randomly arranged within the islet grafts. Similarly as known for pancreatic islets in situ, B cells formed the great central mass of the microorgan, while A and D cells were found primarily at the grafts periphery (Fig. 5). In 42 islets, 181 of $192(94 \%)$ cells/cell clusters positively stained for glucagon,
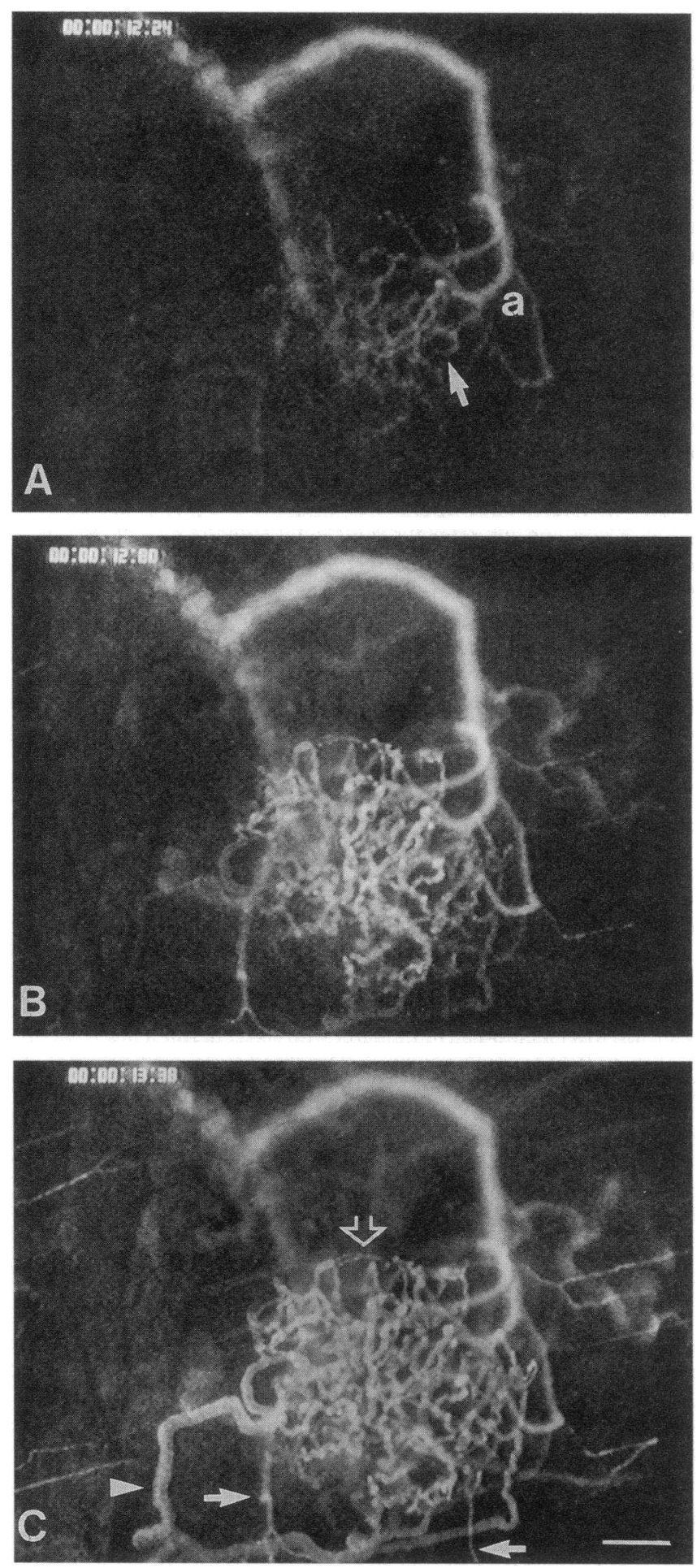

Figure 2. Sequential in vivo fluorescence (FITC-dextran 150,000) microscopic analysis of microvascular perfusion of a syngeneic pancreatic islet $14 \mathrm{~d}$ after transplantation onto striated muscle in hamster. $(A)$ The supplying arteriole $(a)$ penetrates the islet's periphery and breaks into capillaries within the graft $(\rightarrow)$. $(B)$ Capillaries traverse the core of the islet before passing through the mantle of the graft. $(C)$ The islet is drained by an individual venule $(\bullet)$ and islet muscle intercapillary anastomoses $(\rightarrow)$. Note the efferent microvessel of capillary structure $(\Rightarrow)$, running along the periphery of the islet. Bar, $100 \mu \mathrm{m}$. 

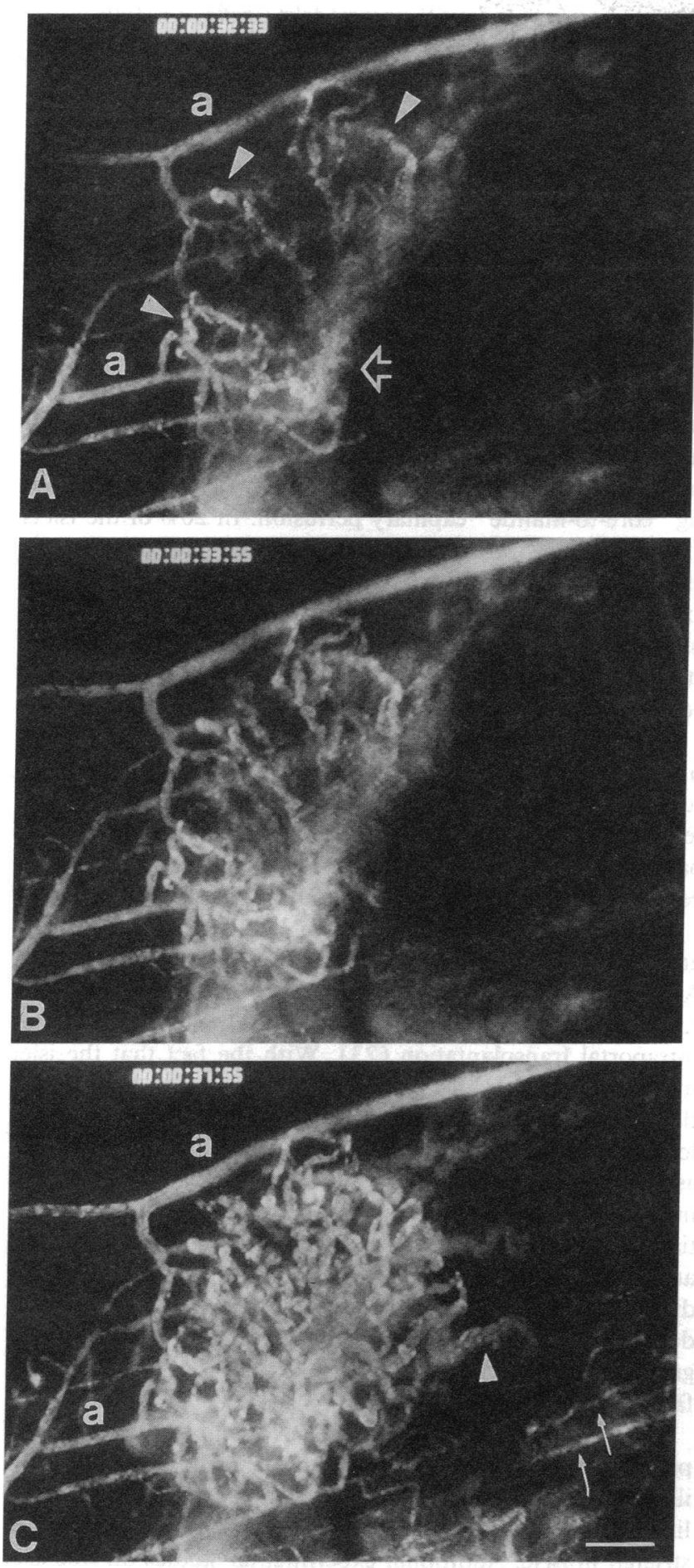

Figure 3. Sequential in vivo fluorescence (FITC-dextran 150,000) microscopic analysis of microvascular perfusion of a syngeneic pancreatic islet $14 \mathrm{~d}$ after transplantation onto striated muscle in hamster. $(A$ and $B$ ) The supplying arterioles $(a)$ break into capillaries at the outer margin of the islet's glomerulum-like microvasculature. Capillary perfusion is simultaneously directed to microvessels located within the core $(\Rightarrow)$ and the periphery $(\triangleright)$ of the graft. $(C)$ The islet is drained by an individual venule $(\bullet)$. Note the supplying arterioles (a) arranged in parallel with the striated muscle capillaries of the host tissue $(\rightarrow)$, indicating their origin from the muscle capillaries. Bar, $100 \mu \mathrm{m}$. and 213 of 224 (95\%) somatostatin-positive cells/cell clusters were scattered within the rim of the grafts.

\section{Discussion}

Several obstacles appear to limit the potential of free islet transplantation as a successful treatment modality of insulin-dependent diabetes mellitus. Beside the difficulties to isolate a sufficient mass of islets necessary for adequate graft function and prevention of (auto) immune response, inadequate vascularization of the grafts is considered as a culprit for hyperglycemia and abnormal glucose tolerance after transplantation (7-9).

With the use of histomorphological analysis, in vivo microscopy and the microspheres technique, recent studies have demonstrated that pancreatic islets transplanted $(a)$ into the liver via the portal vein $(18,19),(b)$ under the renal subcapsular space $(20,21)$, and $(c)$ onto striated muscle $(10,13,15)$ revascularize within $10 \mathrm{~d}$ to $3 \mathrm{wk}$ after transplantation. Although some of these studies precisely describe the arteriolar supply vessels, the nutritive capillaries and the draining venules of the islet grafts, there is no information on the orientation of the islet microvascular blood perfusion. The adequate vascularization of islet grafts, however, may not only require the formation of a dense capillary network to ensure oxygen supply to tissue, but may also include the development of a particular angio-architecture, which guarantees the establishment of an intraislet portal system with $\mathrm{B} \rightarrow \mathrm{A} \rightarrow \mathrm{D}$ sequence of islet cellular perfusion. Weir et al. (7) and Samols et al. (9) assumed that insufficient graft function after islet transplantation may be caused by alteration of the islet's physiologic "core-to-mantle" capillary perfusion (intraislet portal system).

The present study demonstrates that $88 \%$ of the islets transplanted onto striated muscle develop regular "core-to-mantle" capillary perfusion, similar as described for pancreatic islets in situ (3). Most of the islet grafts are supplied by one or two individual arterioles, which pierce into the islet before breaking

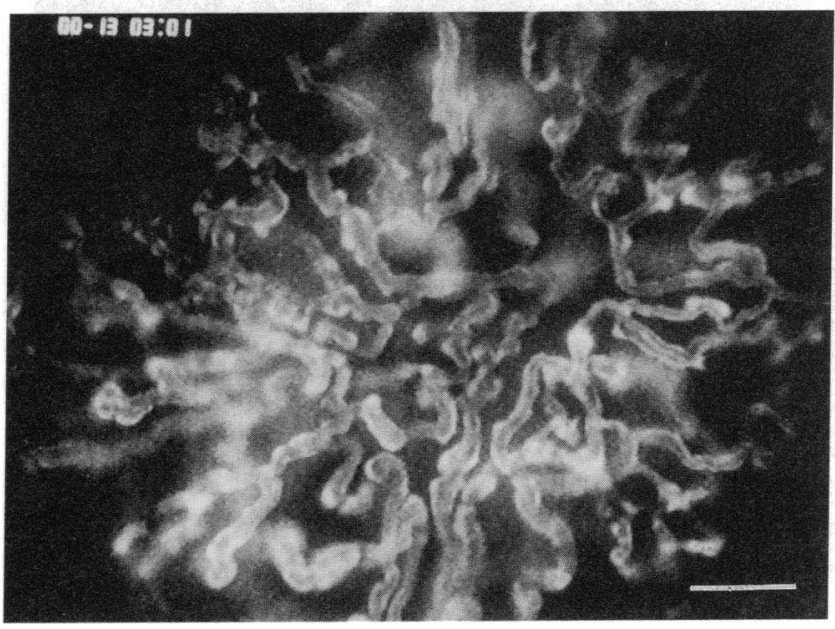

Figure 4. High magnification of the capillary network of a syngeneic pancreatic islet $14 \mathrm{~d}$ after transplantation onto striated muscle in hamster, classified category 3 (see Fig. 1). Note the capillaries, which originate in the center of the islet and radially traverse the graft towards its periphery. In vivo fluorescence microscopy, contrast enhancement with FITC-dextran 150,000 i.v. Bar, $50 \mu \mathrm{m}$. 
Table I. Number and Diameters of Supplying (Arterioles) and Draining (Venules) Microvessels of Syngeneic Islet Grafts ( $n=109)$ 14 d after Transplantation onto Striated Muscle in Hamster

\begin{tabular}{|c|c|c|c|c|c|c|c|}
\hline & \multicolumn{6}{|c|}{ Number of microvessels/islet } & \multirow[b]{2}{*}{$\begin{array}{c}\text { Diameter } \\
\text { mean } \pm \mathrm{SD} \text { (range) }\end{array}$} \\
\hline & 1 & 2 & 3 & 4 & 5 & 6 & \\
\hline & & & & & & & $\mu m$ \\
\hline Arterioles & 56 & 48 & 3 & 2 & - & 一 & $16.8 \pm 3.0(9-30)$ \\
\hline Venules & 19 & 42 & 32 & 11 & 4 & 1 & $20.6 \pm 4.4(11-48)$ \\
\hline
\end{tabular}

into capillaries within the core of the graft. Although we cannot distinguish the core/mantle ( $\mathrm{B} / \mathrm{A}$ and $\mathrm{D}$ cell interface) by in vivo fluorescence microscopy, immunohistochemical staining revealed that B cells occupy the major part of the islet (core), while $A$ and $D$ cells are located mainly within a thin marginal layer at the islet's periphery (Fig. 5). Hence, the arterioles that
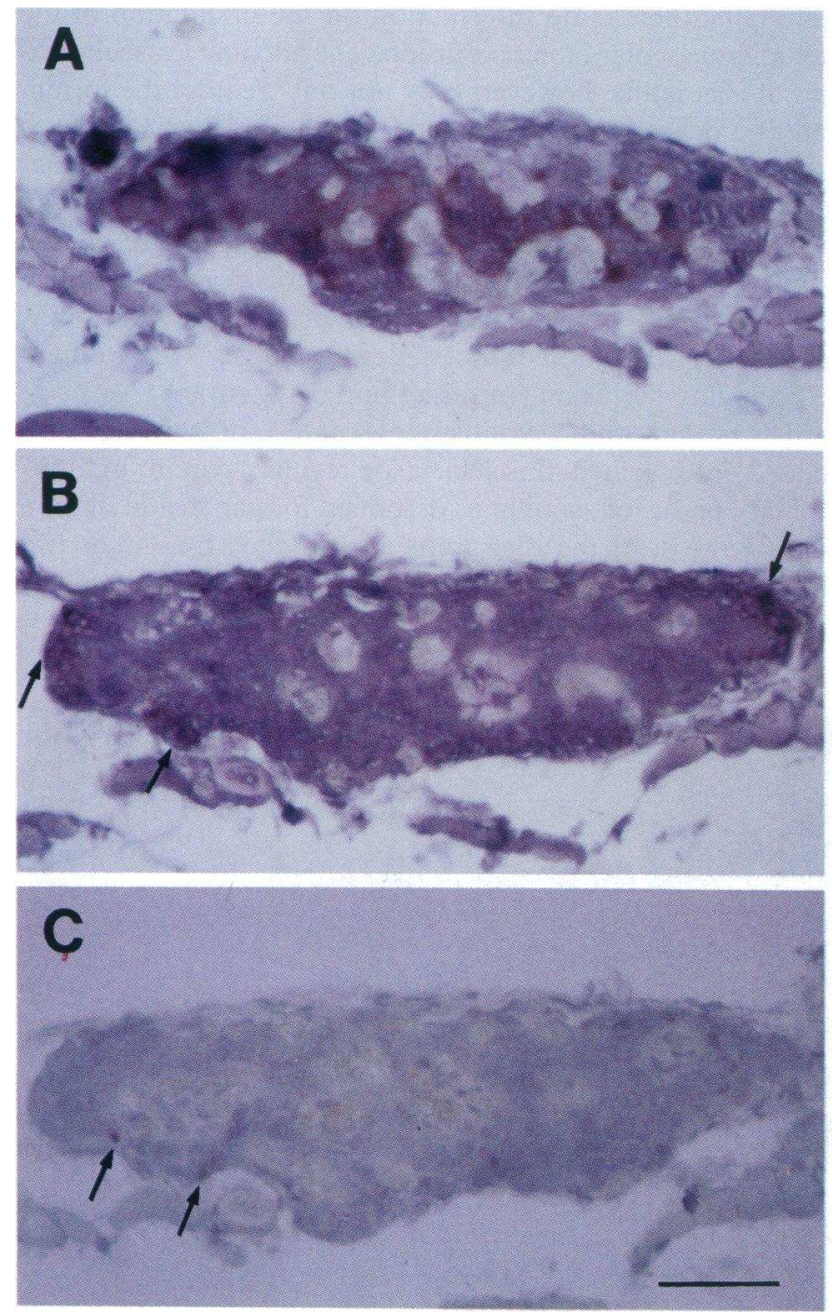

Figure 5. Immunohistochemical staining of syngeneic pancreatic islet graft after transplantation onto striated muscle in hamster. B cells (anti-insulin staining, $A$ ) are visualized in the core of the islet and at discontinuities of the non-B cell mantle, while A cells ( $\rightarrow$ anti-glucagon staining, $B$ ) and $\mathrm{D}$ cells ( $\rightarrow$ anti-somatostatin staining, $C$ ) are scattered only in the islet's periphery. Bar, $50 \mu \mathrm{m}$. pierce the islet (even for only a small distance) before breaking into capillaries (96/109 [88\%] in this study) provide capillary perfusion at first to the B cell core. The capillaries then traverse the islet core before supplying its periphery (Fig. 2), thus proving "core-to-mantle" capillary perfusion. In $26 \%$ of the islets (classified category 3 ), the arterioles even pierced into the center of the graft and capillaries traversed radially the islets towards their periphery (Fig. 4). Only $12 \%$ of the transplanted islets revealed the supplying arteriole breaking into capillaries at the outer margin of the graft (Fig. 3), hence, not providing "core-to-mantle" capillary perfusion.

Capillary blood flow of the islet grafts is drained by one to six individual postcapillary venules, and, in analogy to the insuloacinar portal system, by insulomuscle capillary anastomoses. This corresponds to the vascular drainage system of rat pancreatic islets in situ, which consists of efferent capillaries coalescing into collecting venules outside the islet (3).

The cellular distribution within hamster pancreatic islet grafts with the B cell mass located in the core of the islet and A/D cells scattered at its periphery is similar to that of human, rat, hamster, and mouse islets in situ (22), and rat islets after intraportal transplantation (23). With the fact that the islet microvascular blood flow is directed from the core to the mantle of the graft, our experiments demonstrate a capillary intraislet portal system with sequential B $\rightarrow$ A/D cellular perfusion, as described for pancreatic islets in situ $(1,2,3)$. These findings imply that isolated islets after transplantation have the potential to induce organ-specific angiogenesis for reestablishment of an adequate microvascular angio-architecture, possibly mediated by either cell surface molecules, such as the $\mathrm{Ca}^{2+}$-dependent cell adhesion molecule E cadherin (24), or diffusible growth factors, such as betacellulin (25) or insulin-like growth factor I (26).

In conclusion, we propose that adequate vascularization of pancreatic islets (i.e. individual arteriolar supply, intraislet capillary portal system, and extraislet venular drainage) is established in individual islets after free transplantation onto striated muscle. Additional experimental studies on free islet transplantation to transplantation sites different to that of striated muscle (liver, kidney capsule) have to prove the reestablishment of a similar intraislet portal system, since the orientation of the microvascular blood perfusion may critically influence the physiologic islet cellular communication and glucose homeostasis.

\section{Acknowledgments}

This study was supported in part by the Deutsche Forschungsgemeinschaft Me 900/1-1 and Me 900/1-2. We are greatful to Elke Schütze for technical assistance. We thank Dr. G. Enders for analysis of crossreactivity of anti-porcine insulin antibody by Western blotting. 


\section{References}

1. Samols E., J. I. Stagner, R. B. L. Ewart, and V. Marks. 1988. The order of islet microvascular cellular perfusion is $B \rightarrow A \rightarrow D$ in the perfused rat pancreas. J. Clin. Invest. 82:350-353.

2. Stagner, J. I., and E. Samols. 1992. The vascular order of islet cellular perfusion in the human pancreas. Diabetes. 41:93-97.

3. Bonner-Weir, S., and L. Orci. 1982. New perspectives on the microvasculature of the islets of Langerhans in the rat. Diabetes. 31:883-889.

4. Gray, D. W. R., and P. J. Morris. 1987. Developments in isolated pancreatic islet transplantation. Transplantation (Baltimore). 43:321-331.

5. Lacy, P. E. 1992. Islet transplantation: the future. Diab. Nutr. Metab. 5(Suppl. 1):203-206.

6. Robertson, R. P. 1992. Pancreatic and islet transplantation for diabetes: cures or curiosities? N. Engl. J. Med. 327:1861-1868.

7. Weir, G. C., S. Bonner-Weir, and J. L. Leahy. 1990. Islet mass and function in diabetes and transplantation. Diabetes. 39:401-405.

8. Menger, M. D., and K. Messmer. 1992. Pancreatic islet transplantation: isolation, purification, and microvascularization. Wien. Klin. Wochenschr. 104:429-433.

9. Samols, E., J. I. Stagner, and A. Nakagawa. 1992. Intra-islet and islet-acinar portal systems: relevance to transplantation. Diab. Nutr. Metab. 5(Suppl. 1):3-7.

10. Menger, M. D., S. Jäger, P. Walter, G. Feifel, F. Hammersen, and K. Messmer. 1989. Angiogenesis and hemodynamics of microvasculature of transplanted islets of Langerhans. Diabetes. 38(Suppl. 1):199-201.

11. Menger, M. D., P. Vajkoczy, R. Leiderer, S. Jäger, and K. Messmer. 1992. Influence of experimental hyperglycemia on microvascular blood perfusion of pancreatic islet isografts. J. Clin. Invest. 90:1361-1369.

12. Endrich, B., K. Asaishi, A. Goetz, and K. Messmer. 1980. Technical report: a new chamber technique for microvascular studies in unanesthetized hamsters. Res. Exp. Med. 177:184-196.

13. Menger, M. D., S. Jäger, P. Walter, F. Hammersen, and K. Messmer. 1990. A novel technique for studies on the microvasculature of transplanted islets of Langerhans in vivo. Int. J. Microcirc. Clin. Exp. 9:103-117.

14. Menger, M. D., and H. A. Lehr. 1993. Scope and perspectives of intravital microscopy-bridge over from in vitro to in vivo. Immunol. Today. 14:519-522.
15. Menger, M. D., and K. Messmer. 1991. The microvasculature of pancreatic islet grafts. In Pathways to Applied Immunology. K. Messmer and M. Stein, editors. Springer-Verlag, Berlin. pp. 109-126.

16. Sternberger, L. 1979. Immunocytochemistry. 2nd ed. John Wiley \& Sons, Inc. New York. pp. 104-169.

17. Dawiskiba, S., P. M. Pour, U. Stenram, F. Sundler, and A. AndrénSandberg. 1992. Immunohistochemical characterization of endocrine cells in experimental exocrine pancreatic cancer in the Syrian golden hamster. Int. J. Pancreatol. 11:87-96.

18. Griffith, R. C., D. W. Scharp, B. K. Hartman, W. F. Ballinger, and P. E. Lacy. 1977. A morphologic study of intrahepatic portal-vein islet isografts. Diabetes. 26:201-214.

19. Andersson, A., O. Korsgren, and L. Jansson. 1989. Intraportally transplanted pancreatic islets revascularized from hepatic arterial system. Diabetes. 38(Suppl. 1):192-195.

20. Rooth, P., I. Dawidson, K. Lafferty, K. Diller, J. Armstrong, P. Pratt, R. Simonsen, and I.-B. Täljedal. 1989. Prevention of detrimental effect of cyclosporin A on vascular ingrowth of transplanted pancreatic islets with verapamil. Diabetes. 38(Suppl. 1):202-205.

21. Hayek, A., G. M. Beatti, A. D. Lopez, and P. Chien. 1991. The use of digital image processing to quantitate angiogenesis induced by basic fibroblast growth factor and transplanted pancreatic islets. Microvasc. Res. 41:203-209.

22. Orci, L., and R. H. Unger. 1975. Functional subdivision of islets of Langerhans and possible role of D cells. Lancet. ii:1243-1244.

23. Grotting, J. C., J. Rosai, A. J. Matas, E. M. Frenzel, W. D. Payne, D. E. R. Sutherland, and J. S. Najarian. 1978. The fate of intraportally transplanted islets in diabetic rats. Am. J. Pathol. 92:653-670.

24. Rouiller, D. G., V. Cirulli, and P. A. Halban. 1991. Uvomorulin mediates calcium-dependent aggregation of islet cells, whereas calcium-independent cel adhesion molecules distinguish between islet cell types. Dev. Biol. 148:233-242.

25. Shing, Y., G. Christofori, D. Hanahan, Y. Ono, R. Sasada, K. Igarashi, and J. Folkman. 1993. Betacellulin: a mitogen from pancreatic $\beta$ cell tumors. Science (Wash. DC). 259:1604-1607.

26. Scharfmann, R., M. Corvol, and P. Czernichow. 1989. Characterization of insulinlike growth factor I produced by fetal rat pancreatic islets. Diabetes. 38:686-690. 